\title{
Susceptibility of bacterial etiological agents to commonly-used antimicrobial agents in children with sepsis at the Tamale Teaching Hospital
}

\author{
Samuel EK Acquah ${ }^{1 *}$, Lawrence Quaye ${ }^{2}$, Kenneth Sagoe ${ }^{1}$, Juventus B Ziem³ ${ }^{3}$ Patricia I Bromberger ${ }^{4}$ and
} Anthony A Amponsem ${ }^{1}$

\begin{abstract}
Background: Bloodstream infections in neonates and infants are life-threatening emergencies. Identification of the common bacteria causing such infections and their susceptibility patterns will provide necessary information for timely intervention. This study is aimed at determining the susceptibilities of bacterial etiological agents to commonly-used antimicrobial agents for empirical treatment of suspected bacterial septicaemia in children.

Methods: This is a hospital based retrospective analysis of blood cultures from infants to children up to 14 years of age with preliminary diagnosis of sepsis and admitted to the Neonatal Intensive Care Unit (NICU) and Paediatric Wards of the Teaching Hospital Tamale from July 2011 to January 2012.

Results: Out of 331 blood specimens cultured, the prevalence of confirmed bacterial sepsis was 25.9\% (86/331). Point prevalence for confirmed cases from NICU was 44.4\% (28/63) and 21.6\% (58/268) from the Paediatric ward. Gram positive cocci (GPC) were the predominant isolates with Coagulase positive (32.2\%) and Coagulase-negative (28.7\%) Staphylococci accounting for 60.9\% of the total isolates. Gram negative rods (GNR) comprised 39.1\% of all isolates with Klebsiella, E.coli and Salmonella being the most common organisms isolated. Klebsiella was the most frequent GNR from the NICU and Salmonella typhi was predominantly isolated from the paediatric ward.

Acinetobacter showed $100.0 \%$ susceptibility to Ceftriaxone and Cefotaxime but was resistant (100.0\%) to Ampicillin, Tetracycline and Cotrimoxazole. Escherichia coli and Klebsiella were $80.0 \%$ and $91.0 \%$ susceptible to Ceftriaxone and Cefotaxime respectively. Klebsiella species showed $8.3 \%$ susceptibility to Tetracycline but was resistant to Ampicillin and Cotrimoxazole. Escherichia coli showed $40.0 \%$ susceptibility to Ampicillin, Chloramphenicol and Cotrimoxazole; 20.0\% susceptibility to Tetracycline and $80.0 \%$ susceptible to Gentamicin and Cefuroxime. Coagulase negative Staphylococci was susceptible to Gentamicin (72.0\%) but Coagulase positive Staphylococci showed intermediate sensitivity to Gentamicin (42.9\%).

Conclusion: Coagulase Negative, Coagulase Positive Staphylococci, Salmonella and Klebsiella were the aetiological agents of bloodstream infection among children at TH. While gram-positive and gram-negative bacteria showed low susceptibility to Ampicillin, Tetracycline and Cotrimoxazole, the GNR were susceptible to Gentamicin and thirdgeneration cephalosporins.
\end{abstract}

\footnotetext{
* Correspondence: ekubanus2000@yahoo.co.uk

'Tamale Teaching Hospital, Tamale, Ghana

Full list of author information is available at the end of the article
} 


\section{Background}

The World Health Organization (WHO) reported in 2005 that over 70 percent of deaths in children under age five occur within the first year of life and 40 percent occur within the first month of life [1]. The causes of death according to the report were attributable to malnutrition and infectious diseases [1]. In Ghana the estimated number of deaths among children aged 1-59 months was 32,052, while 22,672 deaths were estimated to have occurred among children 0-27 days, with neonatal sepsis accounting for 4,923 deaths in 2008 [2]. Sepsis is a blood stream infection usually caused by pathogenic bacteria with the diagnosis often beginning with clinical suspicion [3]. However, in children the symptoms are often non-specific, and the clinical course may be fulminant, quickly progressing to a medical emergency that requires urgent attention $[4,5]$. The principal method of diagnosing sepsis is the isolation of causative organisms from blood cultures [6]. In industrialized countries Group B Streptococcus (GBS) and Escherichia coli have been reported as the most frequent bacterial etiological agents of neonatal and infant sepsis $[7,8]$. While Escherichia coli and other gram-negative rods (GNR) have been reported to be responsible for the high morbidity and mortality rates among children in some developing countries [9,10], sepsis among Ghanaian children is predominantly caused by Staphylococcus aureus and non-typhoid Salmonellae [11,12]. Blood culture and antimicrobial susceptibility testing results are usually available between 48-72 hours after the specimen is obtained and therefore initial antimicrobial treatment has been usually empirical with the aim that the most likely pathogens would be susceptible to the chosen drugs [5]. However, this initiative is undermined by the fact that the spectrum of bacteria and their susceptibility patterns may vary over time, depending on the prevailing conditions such as patient population, antimicrobial drug usage and healthcare worker's infection control practices. If not monitored, this could lead to inappropriate use of antibiotics and a subsequent increase in antimicrobial resistant organisms [13-15]. In order to guide empirical therapy, this study reports on bacterial isolates and their susceptibility to commonly-used antimicrobial agents in the empirical treatment of suspected bacterial septicaemia in children presenting at the Tamale Teaching Hospital.

\section{Methods}

\section{Study period/site}

This retrospective study was conducted at the Tamale Teaching Hospital (TTH) from July 2011 to January 2012. TTH is a 340 bed complement hospital situated in the Northern Region of Ghana. In addition to offering clinical care to the inhabitants of Tamale and its surrounding environ, it also serves as a referral hospital to the two Upper regions (Upper East and Upper West) of Ghana. The hospital runs six clinical departments including Paediatrics. With a bed complement of 60 , the Paediatric ward receives admissions from the Children's Emergency Ward (CEW), reporting cases from home or as referrals from other hospitals. The CEW serves as an outpatient clinic to the surrounding population and sees patients up to 14 years of age. The ward has 11 beds for emergency stabilization and holds children for up to 24 hours for treatment with onward admission to the Pediatric ward when hospitalization becomes necessary. All infants less than 30 days of age are admitted to the Neonatal Intensive Care Unit (NICU) which has a bed complement of 17. TTH is an affiliated teaching hospital for the School of Medicine and Health Sciences, University for Development Studies (UDS). Approval for the study was obtained from the Research and Planning Unit for Ethics of TTH.

\section{Data extraction}

Data comprising age, sex, bacterial isolates and their susceptibility reports recorded from July 2011 to January 2012 were extracted from the blood culture entry books of the Bacteriology unit of the hospital's Laboratory Department. All cases of blood culture requested with a preliminary diagnosis of sepsis from a newborn up to 14 years of age admitted at the NICU, children's emergency and the pediatric wards were included in the study.

\section{Laboratory procedures \\ Culture}

Blood specimens were taken into BD Ped culture broth bottles (BD 7 Loveton Circle, Sparks Maryland USA) after thorough cleaning of the venipuncture site and the rubber cap of the bottle with $70 \%$ alcohol. The culture bottles were then incubated at $35^{\circ} \mathrm{C}$ in the BACTEC $^{\circledR} 9050$ blood culture system (BD 7 Loveton Circle, Sparks Maryland USA) for 5 days after which negative indicating specimen are discarded [16,17]. Positive indicated culture bottles were removed and $1 \mathrm{ml}$ of broth aseptically withdrawn from the culture bottles using a sterile syringe and needle. Two drops of the broth were inoculated onto MacConkey Agar, Blood Agar (BA) and Chocolate Agar (CA) plates respectively. The BA and CA plates were placed in candle extinction jars and incubated at $37^{\circ} \mathrm{C}$ for 18 to 24 hours together with the MacConkey plates.

\section{Gram stain}

Gram staining for bacterial identification was performed on heat-fixed smears prepared from the remaining broth following standard bacteriological protocol described by $[18]$. 


\section{Bacterial identification}

Only plates that showed homogenous colony appearance were followed-up for bacterial identification. Conventional identification methods based on characteristics such as morphology, appearance in culture media, physiological and biochemical properties were relied upon to properly identify isolated organisms [18]. The BBL Crystal Auto reader (BD 7 Loveton Circle, Sparks Maryland USA) was employed where conventional methods for identification were inconclusive. Tube coagulase was performed for isolates of gram positive cocci in clusters $[18,19]$. Antimicrobial susceptibility tests were done using the Kirby-Bauer disk diffusion method [20] and interpreted according to the Clinical and Laboratory Standard Institute (CLSI) criteria. Susceptibility testing was controlled with American Type Culture Collection (ATCC) strains: Staphylococcus aureus ATCC 25923, Escherichia coli ATCC 25922 and Pseudomonas aeruginosa ATCC 27853 [21].

\section{Data analysis}

Data retrieved were entered into Microsoft Excel and analyzed using GraphPad Prism $^{\circledR}$ Version 5.0 for Windows (GraphPad Software, San Diego, CA, USA). Descriptive statistics was employed to explain the general distribution of data. Categorical variables were compared using Chi-square test where appropriate. For all statistical comparisons a $p$-value of $<0.05$ was considered statistically significant.

\section{Results}

\section{Study population}

During the study period, spanning July 2011 to January 2012, NICU registered a total of 1074 admissions. The paediatric ward registered a total of 3110 admissions, of which 2537 were received from the Children's Emergency Ward (Institutional care report 2012). The median age of infants with positive blood culture in NICU was 5 days with that for children being 3 years.

\section{Blood cultures}

During the study period, a total of 331 blood cultures with complete demographic and bacteriological data were received. Two hundred and sixty-eight (81.0\%) were from the paediatric ward and $63(19 \%)$ were from NICU. Out of the 331 blood cultures, 97 (29.3\%) were flagged positive. Ten (10) of the positively flagged samples were considered as being contaminated upon the isolation of Corynebacterium species, Bacillus species and Micrococcus species which were considered as contaminants [22,23]. One positive sample vial was indicative of the presence of yeast leaving 86 true positive (pure culture) samples to be followed. The estimated overall contamination rate was 3\% with confirmed bacterial sepsis rate being $26.0 \%(86 / 331)$.

\section{Positive bacterial isolates stratified by ward}

Of the 63 cultures submitted from the NICU, 28 (44\%) were positive out of which $15(35 \%)$ cases were early onset infections (less than 7 days of age) and 13 (42.8\%) cases were late onset infections (greater than 7 days of age.) Of the 268 cultures submitted from the paediatric ward, 58 (21.6\%) were positive for bacterial pathogens.

Upon stratification into their gram reactions, 55 (64.0\%) were gram-positive cocci (GPC) and 31(36.0\%) were gram-negative rods (GNR). Coagulase positive and Coagulase-negative Staphylococci were the predominant GPC isolates recovered from all the wards, accounting for $32.2 \%$ and $28.7 \%$ of the total isolates respectively. For the GNR's, Klebsiella was the most frequent isolate among the neonates and children from the paediatric ward. Escherichia coli were recovered in similar proportions across the wards with Salmonella typhi being the major cause of bacterial sepsis in children admitted to the paediatric ward. Streptococci and Acinetobacter species were only rarely recovered from $\mathrm{NICU}$ and the paediatric ward respectively (Table 1 ).

\section{Antibiotic sensitivity profiles of isolated bacterial pathogens}

Table 2 shows the susceptibilities of the isolated pathogens from the two units. Among the antimicrobials used, thirdgeneration cephalosporins (Ceftriaxone and Cefotaxime) showed good activity against the GNR isolates. Salmonella

Table 1 Bacterial pathogens isolated from the two wards

\begin{tabular}{|c|c|c|c|c|}
\hline \multirow[b]{2}{*}{ Pathogens } & \multicolumn{2}{|c|}{$\begin{array}{c}\text { NICU } \\
(\mathrm{N}=63)\end{array}$} & \multirow{2}{*}{$\begin{array}{c}\text { PAED } \\
(\mathrm{N}=268) \\
\mathrm{n}(\%)\end{array}$} & \multirow{2}{*}{$\begin{array}{c}\begin{array}{c}\text { TOTAL } \\
(\mathrm{N}=331) \\
\mathrm{n}(\%)\end{array}\end{array}$} \\
\hline & $\operatorname{EOS}(\%)$ & $\operatorname{LOS}(\%)$ & & \\
\hline \multicolumn{5}{|l|}{ Gram positive cocci (GPC) } \\
\hline $\begin{array}{l}\text { Coagulase Positive } \\
\text { Staphylococci }\end{array}$ & $3(20.0)$ & $5(38.5)$ & $20(34.5)$ & 28(32.2) \\
\hline $\begin{array}{l}\text { Coagulase Negative } \\
\text { Staphylococci }\end{array}$ & $5(33.3)$ & $5(38.5)$ & $15(25.9)$ & $25(28.7)$ \\
\hline Streptococcus pneumoniae & $0(0.0)$ & $0(0.0)$ & $1(1.7)$ & $1(1.2)$ \\
\hline$\beta$-haemolytic Streptococcus & $0(0.0)$ & $0(0.0)$ & $1(1.7)$ & $1(1.2)$ \\
\hline \multicolumn{5}{|l|}{ Gram negative rods (GNR) } \\
\hline Klebsiella pneumoniae & $2(13.3)$ & $0(0.0)$ & $4(6.9)$ & $6(6.9)$ \\
\hline Escherichia coli & $1(6.7)$ & $1(7.7)$ & $4(6.9)$ & $6(6.9)$ \\
\hline Salmonella typhi & $0(0.0)$ & $0(0.0)$ & $6(10.3)$ & $6(6.9)$ \\
\hline Klebsiella spp & $2(13.3)$ & $0(0.0)$ & $4(6.9)$ & $6(6.9)$ \\
\hline Pseudomonas aeruginosa & $0(0.0)$ & $1(7.7)$ & 2(3.4) & $3(3.5)$ \\
\hline Non-typhoidal Salmonella & $1(6.7)$ & $0(0.0)$ & $1(1.7)$ & $2(2.3)$ \\
\hline Acinetobacter spp & $1(6.7)$ & $1(7.7)$ & $0(0.0)$ & $2(2.3)$ \\
\hline Total isolates & 15 & 13 & 58 & 86 \\
\hline
\end{tabular}

NICU: Neonatal intensive care unit, PAED: Paediatric ward, EOS: Early onset, LOS Late onset. 
Table 2 Bacterial isolates and susceptibility patterns among study population

\begin{tabular}{lcccccccccccc}
\hline & & $\mathbf{G E N}$ & CRX & CHLO & CTR & CTX & AMP & TET & COT & PEN & FLX & ERY \\
\hline Bacteria isolates & $\mathbf{N}$ & $\mathbf{n}(\%)$ & $\mathbf{n}(\%)$ & $\mathbf{n}(\%)$ & $\mathbf{n}(\%)$ & $\mathbf{n}(\%)$ & $\mathbf{n}(\%)$ & $\mathbf{n}(\%)$ & $\mathbf{n}(\%)$ & $\mathbf{n}(\%)$ & $\mathbf{n}(\%)$ & $\mathbf{n}(\%)$ \\
\hline Salmonella spp & $\mathbf{8}$ & - & - & $5(62.5)$ & $8(100.0)$ & $8(100.0)$ & $0(0.0)$ & $0(0.0)$ & $0(0.0)$ & - & - & - \\
Klebsiella spp & $\mathbf{1 2}$ & $4(33.3)$ & $1(8.3)$ & $5(41.7)$ & $11(91.7)$ & $11(91.7)$ & $0(0.0)$ & $1(8.3)$ & $0(0.0)$ & - & - & - \\
Escherichia coli & $\mathbf{6}$ & $4(66.7)$ & $4(66.7)$ & $2(33.3)$ & $4(66.7)$ & $4(66.7)$ & $2(33.3)$ & $1(16.7)$ & $2(33.3)$ & - & - & - \\
Acinetobacter spp & $\mathbf{2}$ & $2(100.0)$ & $0(0.0)$ & $0(0.0)$ & $2(100)$ & $2(100.0)$ & $0(0.0)$ & $0(0.0)$ & $0(0.0)$ & - & - & - \\
Pseudomonas aeruginosa & $\mathbf{3}$ & $1(33.3)$ & - & - & $1(33.3)$ & $1(33.3)$ & - & - & - & - & - & - \\
Coagulase negative Staphylococci & $\mathbf{2 5}$ & $18(72.0)$ & $14(56.0)$ & - & - & - & $1(4.0)$ & $6(24.0)$ & $5(20.0)$ & $1(4.0)$ & $10(40.0)$ & $13(52.0)$ \\
Coagulase positive Staphylococci & $\mathbf{2 8}$ & $12(42.9)$ & $16(57.1)$ & - & - & - & $1(3.6)$ & $2(25)$ & $2(7.1)$ & $1(3.6)$ & $8(28.6)$ & $10(35.7)$ \\
\hline
\end{tabular}

GEN-Gentamicin, CRX-Cefuroxime, CHLO-Chloramphenicol, CTR-Ceftriaxone, CTX-Cefotaxime, AMP-Ampicillin, TET-Tetracycline, COT-Cotrimoxazole, PEN-Penicillin, FLX-Flucloxacillin, ERY-Erythromycin, (-) - Not done, Salmonella spp= Salmonella spp and Salmonella typhi, Klebsiella spp = Klebsiella spp and Klebsiella pneumoniae.

and Acinetobacter showed $100.0 \%$ susceptibility, while Escherichia coli and Klebsiella were $80.0 \%$ and $91.0 \%$ susceptible to Ceftriaxone and Cefotaxime respectively. Salmonella and Acinetobacter were $100.0 \%$ resistant to Ampicillin, Tetracycline and Cotrimoxazole. Klebsiella species showed $8.3 \%$ susceptibility to Tetracycline but were $100.0 \%$ resistant to Ampicillin and Cotrimoxazole. Escherichia coli showed variable susceptibility to the tested antimicrobials with $40.0 \%$ susceptible to Ampicillin, Chloramphenicol and Cotrimoxazole; $20.0 \%$ susceptible to Tetracycline; and $80.0 \%$ susceptible to Gentamicin and Cefuroxime. The susceptibility of Pseudomonas aeruginosa to the commonly used antimicrobials, Gentamicin, Ceftriaxone, and Cefotaxime, is as shown in Table 2. Levels of susceptibility of the GPC to the available antimicrobials also varied greatly. Most Coagulase positive Staphylococci (96.4\%) and the Coagulase negative Staphylococci (96.0\%) were resistant to Ampicillin and Penicillin. Coagulase negative Staphylococci was often sensitive to Gentamicin (72.0\%) but Coagulase positive Staphylococci had only intermediate sensitivity to Gentamicin (42.9\%) (Table 2).

\section{Discussion}

Bloodstream infection remains a major cause of morbidity and prolonged hospital stay in children [24]. In neonates and infants, it is a life-threatening emergency, and therefore identifying the common bacteria and their susceptibility patterns will provide information necessary for timely intervention $[25,26]$. Unfortunately there is limited information about the spectrum of pathogens causing infection and their antibiotic susceptibility in many under-resourced areas [27]. Over the six months study period, this study showed a $25.9 \%$ positivity rate for isolated bacterial pathogens. This could most likely represent an under-estimation of the true prevalence of bacterial septicaemia as many of the infants and children cared for in NICU and the paediatric ward respectively received empirical treatment with antibiotics before blood was drawn for culture. Polage et al. [28] iterated this fact in their study on laboratory use in Ghana where they concluded that physician perception regarding the value of diagnostic testing has been a major potential barrier to laboratory use resulting in empiricism and disproportionate antimicrobial administration. The estimated positivity rate for isolated bacterial pathogens from this study is however lower than rates found in University of Calabar Teaching Hospital (48.9\%) and University of Port Harcourt Teaching Hospital (34.2\%) in Nigeria [29,30].

The spectrum of gram-negative bacteria responsible for neonatal sepsis in this study is similar to that reported by other authors [31-33] with the predominant isolates being Klebsiella and Escherichia coli. Klebsiella may be regarded as normal flora in many parts of the body. They colonize the skin, pharynx, and the gastrointestinal tract. They may, however, be associated with chorioamnionitis, urogenital infection or urinary tract infection in the mother. Neonates could therefore acquire these organisms before and/or during delivery from their mothers with infections at the time of delivery or shortly thereafter [34].

As reported in other studies [35,36], the GPC were the predominant bacteria isolates in both early and late onset sepsis from NICU. The high proportions of CoNS isolated in both early onset (33.3\%) and late onset (38.5\%) at the NICU gives a suggestion of CoNS as an emerging pathogen in the unit [37]. However, the diagnosis of CoNS in bloodstream infections is problematic. Generally, CoNS is not thought to be a cause of EOS, although it has been reported in studies reviewing organisms causing early infections [38,39]. Conversely, CoNS is the predominant cause of LOS in low birth weight infants and infants who have indwelling catheters or other instrumentation $[40,41]$. The isolation of CoNS in blood cultures is considered to be pathogenic if it is obtained from at least two separate sites, a process which may be difficult in infants [40]. Therefore the combination of isolation of CoNS from the bloodstream with clinical symptoms of neonatal infection may be the best approach for determining pathogenicity of the 
CoNS $[41,42]$. Since CoNS is the predominant bacteria colonizing the skin, it is very easy to contaminate the blood culture during the process of venipuncture. The optimal technique for obtaining blood cultures specifies povidone-iodine or chlorhexidine as skin-cleansing agents and venipuncture techniques that minimize contamination by skin flora [41]. Generally, 70\% alcohol serves as the major cleansing agent of the skin in resource-limited areas in view of perennial unavailability of povidone and chlorhexidine in both the NICU and paediatric wards. These factors suggest that the high proportion of the CoNS isolated is more likely to be contamination from the skin $[26,43]$.

Consistent with other studies [44,45], Streptococcal species were recovered infrequently from neonates with early onset (EOS) in this study. There is an on-going debate about the importance of GBS infections in subSaharan Africa [46,47]. Although most studies report that GBS infections are rare in Africa, studies in Malawi, Kenya, South Africa and Zimbabwe report that maternal colonization and EOS infections rates are similar to those reported from the United States and Europe [48]. It has been hypothesized that the overwhelming nature of the infection in the neonate with early death, a predominantly out-born population, the infrequency of obtaining blood cultures in sick infants, and the fastidious culture requirements to identify GBS might interfere with its identification as a major pathogen in the neonatal period [48]. Other authors suggest that the cause of EOS is gradually shifting from vertical transmission to acquisition of infection from immediate exposure to environment such as hands of health-care workers or unclean delivery practices $[44,45]$. The yield of GBS from blood cultures is greatly influenced by many factors such as methodology of obtaining blood cultures, recent or intrapartum antibiotic use, and requirement for specialized media [49]. Interpretation of results from this study should be done cautiously as most of these factors were not factored into the inclusion criteria per the design of the study.

In spite of the fact that late-onset (LOS) neonatal infection may occur through vertical transmission during passage through the birth canal leading to colonization and, later, to infection [50], the majority of the LOS in newborn infants is usually hospital-acquired infection [26]. Although some of the blood cultures from babies greater than seven days of age were obtained from infants who had been admitted to the NICU immediately after birth and then became sick (representing hospital-acquired infection), many of the babies who had blood cultures drawn in the NICU were admitted directly from home or from the outpatient department after seven days of age. Infants, less than 30 days of age are also admitted to the NICU rather than the paediatric ward. Isolates from these admissions therefore, are more likely to represent community-acquired rather than hospital- associated late onset infections.

Other studies have reported non-typhoid Salmonella as the most frequent cause of bloodstream infection in older children $[11,51,52]$ however the predominant Salmonella species isolated from the paediatric wards in this study was Salmonella typhi. It has been suggested that in addition to poor personal hygiene of caretakers and environmental contaminations, young children are more susceptible to Salmonella infection because they possess immature gut lymphoid tissues and have decreased gastric acidity $[11,53]$. This finding underscores the need for increased awareness and knowledge about cleanliness and environmental sanitation for healthy living in the communities.

As observed from the current study, both the grampositive $(4 \%-25 \%)$ and gram-negative $(0 \%-40 \%)$ bacteria showed very low sensitivity to Ampicillin and Cotrimoxazole. However the gram negative bacteria displayed high levels of susceptibility to the thirdgeneration cephalosporins with the exception of Pseudomonas aeruginosa. Gentamicin was effective against Escherichia coli (80\%), Acinetobacter (100\%) and the CoNS (72\%), but Klebsiella (33.3\%), Pseudomonas (33.3\%) and Coagulase positive Staphylococci (42.9\%) were often resistant to Gentamicin.

The recommended empiric antibiotic therapy for EOS has been Ampicillin and an aminoglycoside, usually Gentamicin, while in LOS a third-generation cephalosporin in combination with Ampicillin is used [54,55]. The noteworthy findings of this study are the susceptibilities of the GNR to Gentamicin and third-generation cephalosporins. Many authors report increasing GNR resistance to both Gentamicin and third-generation cephalosporins in developing countries which may be related to frequent and unrestricted use of third-generation cephalosporins [56-59]. It has been suggested that over-use of thirdgeneration cephalosporins is also linked to increased risk of neonatal death [60], increased risk for necrotizing enterocolitis in low birth-weight infants [61] and increased risk for invasive candidiasis [62]. Of particular interest are some Acinetobacter species that have emerged in Southeast Asia and Africa that are multi-drug resistant $[63,64]$. Results from this study shows that the isolated GNRs are still fairly susceptible to thirdgeneration cephalosporins. First-line empiric therapy for rule-out sepsis at the NICU in TTH currently utilizes a combination drug comprising Ampicillin and Gentamicin while the third-generation cephalosporins are only used very selectively, a practice that may reduce risk for multi-drug resistant bacterial strains.

\section{Conclusions}

This review identified Coagulase Negative, Coagulase Positive Staphylococci, Salmonella and Klebsiella as 
predominant aetiological agents of bloodstream infection among children at TTH. While both the gram-positive and gram- negative bacteria showed very low susceptibility to Ampicillin, Tetracycline and Cotrimoxazole, the GNR were fairly susceptible to Gentamicin and third-generation cephalosporins. Further studies to identify risk factors for developing sepsis and designing interventions to reduce bloodstream infections in the wards and the communities should be piloted.

\section{Limitations}

Factors such as recent or intrapartum antibiotic use and requirement for specialized media were not factored into the inclusion criteria per the design of the study. Data for this study were obtained over the course of seven months between July 2011 and January 2012, and therefore seasonal variations in the frequency of bloodstream infection and causative microorganisms could not be assessed.

\section{Competing interests}

We declare that we have no competing interests.

\section{Authors' contributions}

SEKA carried out the cultures, designed and drafted the manuscript, LQ performed the statistical analysis and participated in the drafting of the manuscript, PIB, KS, JBZ and AAB coordinated the study and participated in the drafting of the manuscript. All authors read and approved the final manuscript.

\section{Acknowledgements}

We wish to express our profound gratitude to all children and staff of the NICU, Paediatric and Children Emergency wards and the Bacteriology Laboratory of the Tamale Teaching Hospital.

\section{Author details}

${ }^{1}$ Tamale Teaching Hospital, Tamale, Ghana. ${ }^{2}$ Department of Medical Laboratory Services, School of Medicine and Health Sciences University for Development Studies, Tamale, Ghana. ${ }^{3}$ School of Medicine and Health Sciences University for Development Studies, Tamale, Ghana. ${ }^{4}$ Department of Neonatology, Southern California Kaiser Permanente Medical Group, San Diego, CA, USA.

Received: 14 June 2012 Accepted: 7 February 2013

Published: 18 February 2013

\section{References}

1. WHO, World health report 2005: Make every mother and child count. Geneva: WHO; 2005:2005

2. Black RE, Cousens S, Johnson HL, Lawn JE, Rudan I, Bassani DG, Jha P, Campbell H, Walker CF, Cibulskis R, Eisele T, Liu L, Mathers C: Global, regional, and national causes of child mortality in 2008: a systematic analysis. Lancet 2010, 375:1969-1987.

3. Daniels R: Surviving the first hours in sepsis: getting the basics right (an intensivist's perspective). J Antimicrob Chemother 2011, 66(suppl 2):ii11-ii23.

4. Ng PC, Cheng SH, Chui KM, Fok TF, Wong MY, Wong W, Wong RP, Cheung $\mathrm{KL}$ : Diagnosis of late onset neonatal sepsis with cytokines, adhesion molecule, and C-reactive protein in preterm very low birthweight infants. Arch Dis Child Fetal Neonatal Ed 1997, 77(3):F221-F227.

5. Muller-Pebody B, Johnson AP, Heath PT, Gilbert RE, Henderson KL, Sharland M: Empirical treatment of neonatal sepsis: are the current guidelines adequate? Arch Dis Child Fetal Neonatal Ed 2010, 96(1):F4-F8.

6. Iregbu KC, Elegba OY, Babaniyi IB: Bacteriological profile of neonatal septicaemia in a tertiary hospital in nigeria. Afr Health Sci 2006, 6(3):151-154.

7. Hyde TB, Hilger TM, Reingold A, Farley MM, O'Brien KL, Schuchat A: Trends in incidence and antimicrobial resistance of early-onset sepsis: population-based surveillance in San francisco and atlanta. Pediatrics 2002, 110(4):690-695.

8. Isaacs D: To kill or to let die? J Paediatr Child Health 2003, 39(2):135-136.

9. Tallur SS, Kasturi AV, Nadgir SD, Krishna BV: Clinico-bacteriological study of neonatal septicemia in hubli. Indian J Pediatr 2000, 67(3):169-174.

10. Karthikeyan G, Premkumar K: Neonatal sepsis: staphylococcus aureus as the predominant pathogen. Indian J Pediatr 2001, 68(8):715-717.

11. Evans JA, Adusei A, Timmann C, May J, Mack D, Agbenyega T, Horstmann $\mathrm{RD}$, Frimpong E: High mortality of infant bacteraemia clinically indistinguishable from severe malaria. QJM 2004, 97(9):591-597.

12. Schwarz NG, Sarpong N, Hunger F, Marks F, Acquah SE, Agyekum A, Nkrumah B, Loag W, Hagen RM, Evans JA, Dekker D, Fobil JN, Meyer CG, May J, Adu-Sarkodie Y: Systemic bacteraemia in children presenting with clinical pneumonia and the impact of non-typhoid salmonella (NTS). BMC Infect Dis 2010, 10:319.

13. Kollef MH: Inadequate antimicrobial treatment: an important determinant of outcome for hospitalized patients. Clin Infect Dis 2000, 31(Suppl 4):S131-S138.

14. Fiel S: Guidelines and critical pathways for severe hospital-acquired pneumonia. Chest 2001, 119(2 Suppl):412S-418S.

15. Bellissimo-Rodrigues F: Antimicrobial drug use and antibiotic-resistant bacteria. Emerg Infect Dis 2008, 14(1):187. author reply, 187-8.

16. Hardy DJ, Hulbert BB, Migneault PC: Time to detection of positive BacT/ alert blood cultures and lack of need for routine subculture of 5- to 7-day negative cultures. J Clin Microbiol 1992, 30(10):2743-2745.

17. Baron EJ, Scott JD, Tompkins LS: Prolonged incubation and extensive subculturing do not increase recovery of clinically significant microorganisms from standard automated blood cultures. Clin Infect Dis 2005, 41(11):1677-1680.

18. Cheesbrough M: District laboratory practice in tropcal countries part II. 2nd edition. UK: Cambridge University Press; 2009.

19. Garcia LS: Clinical microbiology procedures handbook, vloumes 1-3. 3rd edition. American Society for Microbiology (ASM); 2010.

20. Bauer AW, Kirby WM, Sherris JC, Turck M: Antibiotic susceptibility testing by a standardized single disk method. Am J Clin Pathol 1966, 45(4):493-496.

21. CLSI, Clinical and Laboratory Standards Institute Performance standards for antimicrobial susceptibility testing: 18th Informational supplement, M100-S18. Wayne, PA: Clinical and Laboratory Standards Institute; 2008.

22. Bates DW, Goldman L, Lee TH: Contaminant blood cultures and resource utilization. The true consequences of false-positive results. JAMA 1991, 265(3):365-369.

23. Weinstein MP: Blood culture contamination: persisting problems and partial progress. J Clin Microbiol 2003, 41(6):2275-2278.

24. Slonim AD, Kurtines HC, Sprague BM, Singh N: The costs associated with nosocomial bloodstream infections in the pediatric intensive care unit. Pediatr Crit Care Med 2001, 2(2):170-174.

25. Yurdakok M: Antibiotic use in neonatal sepsis. Turk J Pediatr 1998, 40(1):17-33.

26. Modi N, Dore CJ, Saraswatula A, Richards M, Bamford KB, Coello R, Holmes A: A case definition for national and international neonatal bloodstream infection surveillance. Arch Dis Child Fetal Neonatal Ed 2009, 94(1):F8-F12.

27. Lubell Y, Ashley EA, Turner C, Turner P, White NJ: Susceptibility of community-acquired pathogens to antibiotics in Africa and Asia in neonatesan alarmingly short review. Trop Med Int Health 2011, 16(2):145-151.

28. Polage CR, Bedu-Addo G, Owusu-Ofori A, Frimpong E, Lloyd W, Zurcher E, Hale D, Petti CA: Laboratory use in ghana: physician perception and practice. AmJTrop Med Hyg 2006, 75(3):526-531.

29. Meremikwu MM, Nwachukwu CE, Asuquo AE, Okebe JU, Utsalo SJ: Bacterial isolates from blood cultures of children with suspected septicaemia in calabar, Nigeria. BMC Infect Dis 2005, 5:110.

30. Adedokun AA, Frank-Peterside N, Awah IJ, Obunge OK, Omakwele GCS: Incidence of septicaemia in children attending the university of port harcourt teaching hospital, PortHarcourt south-south Nigeria. International Science and Investigation journal 2012, 23:106.

31. Ahmed AS, Chowdhury MA, Hoque M, Darmstadt GL: Clinical and bacteriological profile of neonatal septicemia in a tertiary level pediatric hospital in bangladesh. Indian Pediatr 2002, 39(11):1034-1039.

32. Aftab R, lqbal I: Bacteriological agents of neonatal sepsis in NICU at nishtar hospital multan. J Coll Physicians Surg Pak 2006, 16(3):216-219. 
33. Aletayeb SMH, Khosravi AD, Dehdashtian M, Kompani F, Mortazavi SM, Aramesh MR: Identification of bacterial agents and antimicrobial susceptibility of neonatal sepsis: A 54-month study in a tertiary hospital. African Journal of Microbiology Research 2011, 5(5):528-531.

34. Prober CG: Bacterial resistance and the dilemma of antibiotic usage. West J Med 1997, 166(5):337-338.

35. Milledge J, Calis JC, Graham SM, Phiri A, Wilson LK, Soko D, Mbvwinji M, Walsh AL, Rogerson SR, Molyneux ME, Molyneux EM: Aetiology of neonatal sepsis in blantyre, malawi: 1996-2001. Ann Trop Paediatr 2005, 25(2):101-110.

36. Mugalu J, Nakakeeto MK, Kiguli S, Kaddu-Mulindwa DH: Aetiology, risk factors and immediate outcome of bacteriologically confirmed neonatal septicaemia in mulago hospital, uganda. Afr Health Sci 2006, 6(2):120-126.

37. Fadel HJ, Patel R, Vetter EA, Baddour LM: Clinical significance of a single staphylococcus lugdunensis-positive blood culture. J Clin Microbiol 2011, 49(4):1697-1699.

38. Ogunlesi TA, Ogunfowora OB, Osinupebi O, Olanrewaju DM: Changing trends in newborn sepsis in sagamu, nigeria: bacterial aetiology, risk factors and antibiotic susceptibility. J Paediatr Child Health 2011, 47(1-2):5-11.

39. Sgro M, Shah PS, Campbell D, Tenuta A, Shivananda S, Lee SK: Early-onset neonatal sepsis: rate and organism pattern between, 2003 and 2008. J Perinatol 2011, 31(12):794-798.

40. Craft A, Finer N: Nosocomial coagulase negative staphylococcal (CoNS) catheter-related sepsis in preterm infants: definition, diagnosis, prophylaxis, and prevention. J Perinatol 2001, 21(3):186-192.

41. Rubin LG, Sanchez PJ, Siegel J, Levine G, Saiman L, Jarvis WR: Evaluation and treatment of neonates with suspected late-onset sepsis: a survey of neonatologists' practices. Pediatrics 2002, 110(4):e42

42. Natoli S, Fontana C, Favaro M, Bergamini A, Testore GP, Minelli S, Bossa MC, Casapulla M, Broglio G, Beltrame A, Cudillo L, Cerretti R, Leonardis F: Characterization of coagulase-negative staphylococcal isolates from blood with reduced susceptibility to glycopeptides and therapeutic options. BMC Infect Dis 2009, 9:83

43. Moureau NL: Are your skin-prep and catheter maintenance techniques up-to-date? Nursing 2009, 39(5):15-16

44. Lautenbach E, Polk RE: Resistant gram-negative bacilli: A neglected healthcare crisis? Am J Health Syst Pharm 2007, 64(23 Suppl 14):S3-21. quiz S22-4.

45. Orsi GB, d'Ettorre G, Panero A, Chiarini F, Vullo V, Venditti M: Hospitalacquired infection surveillance in a neonatal intensive care unit. Am J Infect Control 2009, 37(3):201-203.

46. The WHO Young Infants Study Group: Conclusions from the WHO multicenter study of serious infections in young infants. Pediatr Infect Dis J 1999, 18(10 Suppl):S32-S34.

47. Seale AC, Mwaniki M, Newton CR, Berkley JA: Maternal and early onset neonatal bacterial sepsis: burden and strategies for prevention in subsaharan africa. Lancet Infect Dis 2009, 9(7):428-438.

48. Gray KJ, Bennett SL, French N, Phiri AJ, Graham SM: Invasive group B streptococcal infection in infants, malawi. Emerg Infect Dis 2007, 13(2):223-229.

49. Verani JR, McGee L, Schrag SJ: Prevention of perinatal group B streptococcal disease. Morbidity and Mortality Weekly Report (MMWR), Revised Guidelines from CDC, Recommendations and Reports 2010, 59(RR10):1-32

50. Jiang $\mathrm{JH}$, Chiu NC, Huang FY, Kao HA, Hsu CH, Hung HY, Chang JH, Peng CC: Neonatal sepsis in the neonatal intensive care unit: characteristics of early versus late onset. J Microbiol Immunol Infect 2004, 37(5):301-306.

51. Green SD, Cheesbrough JS: Salmonella bacteraemia among young children at a rural hospital in western zaire. Ann Trop Paediatr 1993, 13(1):45-53

52. Brent AJ, Oundo JO, Mwangi I, Ochola L, Lowe B, Berkley JA: Salmonella bacteremia in kenyan children. Pediatr Infect Dis J 2006, 25(3):230-236.

53. Hung TY, Liu MC, Hsu CF, Lin YC: Rotavirus infection increases the risk of bacteremia in children with nontyphoid salmonella gastroenteritis. Eur $J$ Clin Microbiol Infect Dis 2009, 28(4):425-428.

54. Klein JO: From harmless commensal to invasive pathogen-coagulasenegative staphylococci. N Engl J Med 1990, 323(5):339-340.

55. Pickering LK, Baker CJ, Kimberlin DW, Long SS: Red book: 2009 report of the committee on infectious diseases. 28th edition. Elk Grove Village, IL: 2009, American Academy of Pediatrics; 2009.
56. Gordon A, Isaacs D: Late-onset infection and the role of antibiotic prescribing policies. Curr Opin Infect Dis 2004, 17(3):231-236.

57. Linkin DR, Fishman NO, Patel JB, Merrill JD, Lautenbach E: Risk factors for extended-spectrum beta-lactamase-producing enterobacteriaceae in a neonatal intensive care unit. Infect Control Hosp Epidemiol 2004, 25(9):781-783.

58. Krishna BVS, Patil AB, Chandrasekhar MR: Extended spectrum beta lactamase producing klebsiella pneumoniae in neonatal intensive care unit. Indian J Pediatr 2007, 74(7):627-630.

59. Thaver D, Ali SA, Zaidi AK: Antimicrobial resistance among neonatal pathogens in developing countries. Pediatr Infect Dis J 2009, 28(1 Suppl): S19-S21.

60. Clark RH, Bloom BT, Spitzer AR, Gerstmann DR: Empiric use of ampicillin and cefotaxime, compared with ampicillin and gentamicin, for neonates at risk for sepsis is associated with an increased risk of neonatal death. Pediatrics 2006, 117(1):67-74.

61. Cotten CM, Taylor S, Stoll B, Goldberg RN, Hansen NI, Sanchez PJ, Ambalavanan N, Benjamin DK Jr: Prolonged duration of initial empirica antibiotic treatment is associated with increased rates of necrotizing enterocolitis and death for extremely low birth weight infants. Pediatrics 2009, 123(1):58-66.

62. Cotten CM, McDonald S, Stoll B, Goldberg RN, Poole K, Benjamin DK Jr: The association of third-generation cephalosporin use and invasive candidiasis in extremely low birth-weight infants. Pediatrics 2006, 118(2):717-722.

63. Saleem AF, Ahmed I, Mir F, Ali SR, Zaidi AK: Pan-resistant acinetobacter infection in neonates in karachi, pakistan. J Infect Dev Ctries 2009, 4(1):30-37.

64. Roy S, Viswanathan R, Singh A, Das P, Basu S: Gut colonization by multidrug-resistant and carbapenem-resistant acinetobacter baumannii in neonates. Eur J Clin Microbiol Infect Dis 2010, 29(12):1495-1500.

doi:10.1186/1471-2334-13-89

Cite this article as: Acquah et al.: Susceptibility of bacterial etiological agents to commonly-used antimicrobial agents in children with sepsis at the Tamale Teaching Hospital. BMC Infectious Diseases 2013 13:89.

\section{Submit your next manuscript to BioMed Central and take full advantage of:}

- Convenient online submission

- Thorough peer review

- No space constraints or color figure charges

- Immediate publication on acceptance

- Inclusion in PubMed, CAS, Scopus and Google Scholar

- Research which is freely available for redistribution 